\title{
Elasticity coefficient for forecasting of the developing alternative routes results
}

\author{
Vladimir Zyryanov ${ }^{1}$, and Olga Bulatova ${ }^{1 *}$ \\ ${ }^{1}$ Don State Technical University, 344000 Rostov-on-Don, Russia
}

\begin{abstract}
This article represents the methodology of the transport flows elasticity in condition of two alternative routes. The planning of alternative routes demands the methodology of transport flows elasticity. As an example was taken one of the routes in Rostov-on-Don (Russia). A transport tunnel as alternative route was offered to redistribute transport flows. To assume transport flows behavior the elasticity coefficient was calculated. It showed the effect of tunnel implementation. Considering coefficient gives a clear idea if the implementation alternative route is efficient.
\end{abstract}

\section{Introduction}

High number of cars compromises quality of transport network function. It makes transport demand higher than transport network capacity. The economic indicators are affected. Alternative implementing of routes could be a solution for this problem. The effect of the implementation needs analyzing to avoid different risks. The planning of alternative routes demands the methodology of transport flows elasticity $[1-3,5-8,12]$.

\section{Theory}

The transport elasticity coefficient could show changes by different factors. The negative sign of the elasticity coefficient is the opposite effect from the influencing factors in the studied process $[3,4,9]$.

The coefficient of transport flows elasticity was offered, it can be obtained by:

$$
\eta=\frac{Q_{2}^{x}-Q_{1}^{x}}{Q_{1}^{x}} \cdot \frac{P_{2}^{y}-P_{1}^{y}}{P_{1}^{y}},
$$

where $\eta$ - coefficient of transport flows elasticity, $Q_{1}^{x}, Q^{x}{ }_{2}$ - transport demand on the route $X$ before and after developing alternative routes, $P^{x_{1}}, P^{x_{2}}-$ transport demand on the route $Y$ before and after developing alternative routes.

It is better to use the cross elasticity coefficient for the forecasting the transport flows behavior in the two alternative routes conditions:

\footnotetext{
* Corresponding author: olga-krivolapova@yandex.ru
} 


$$
\eta=\frac{Q_{2}^{x}-Q_{1}^{x}}{Q_{2}^{x}+Q_{1}^{x}} \cdot \frac{P_{2}^{y}-P_{1}^{y}}{P_{2}^{y}-P_{1}^{y}},
$$

where $\eta$ - coefficient of transport flows elasticity, that could show changes by different factors, $Q^{x}{ }_{1}, Q^{x}{ }_{2}$ - transport demand on the route $X$ before and after developing alternative routes, $P^{x}{ }_{1}, P^{x}{ }_{2}$ - transport demand on the route $Y$ before and after developing alternative routes.

For better understanding the consequences of the developing new route, it is necessary to make a model of the situation.

Picture 1 shows four steps of it (figure 1):

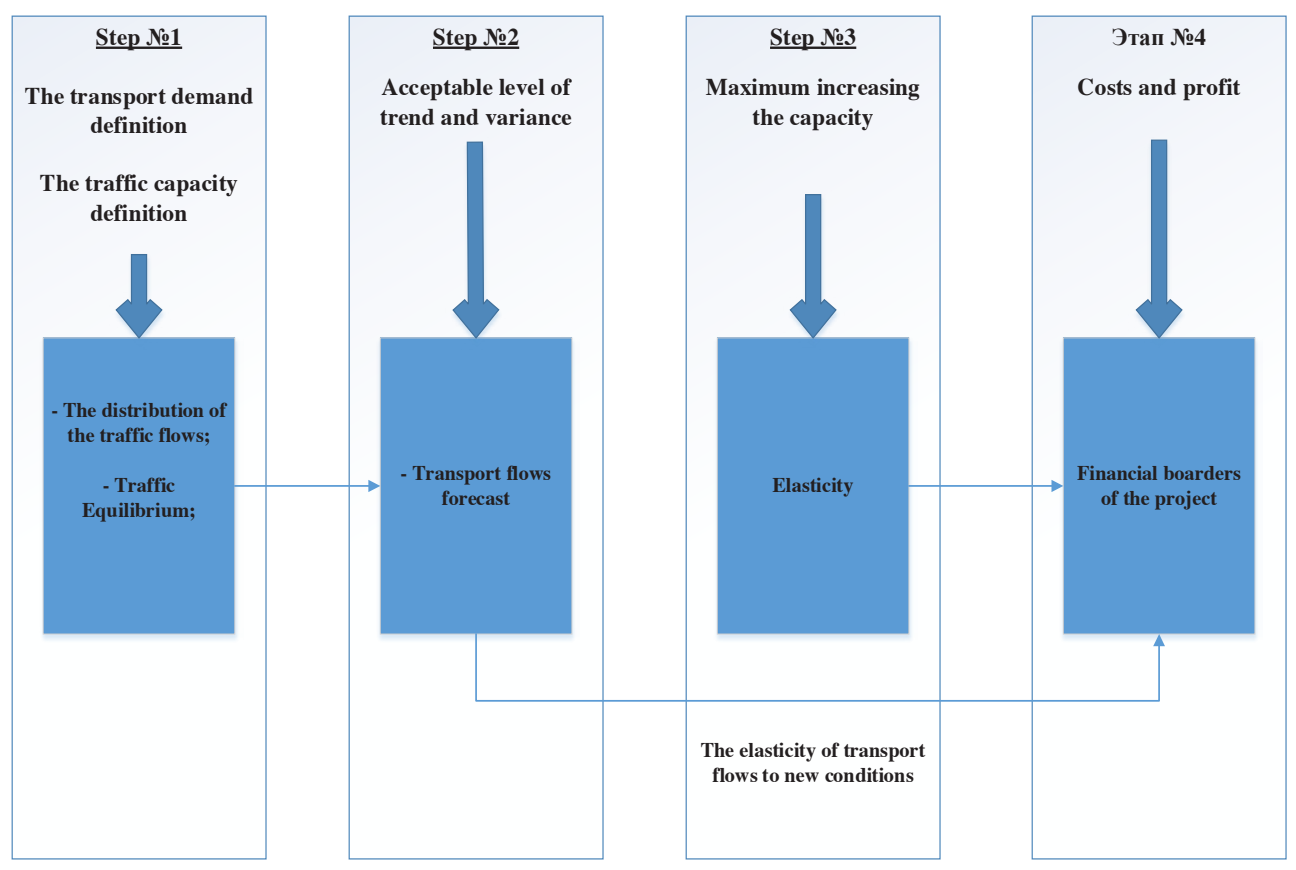

Fig. 1. The modelling of the new routes influence

\section{Results and Discussion}

For the modelling and utilizing the cross elasticity coefficient the data of the problematic part of Rostov-on-Don transport's network were studied (figure 2) [13, 14].

The modelling conditions had 2 scenarios: the first one is without alternative route, the second - redistribution of transport flows between two alternative routes. Pics. 3, 4 show: speed of transport flows in the first scenario is $26 \mathrm{~km} / \mathrm{h}$, in the second $-31 \mathrm{~km} / \mathrm{h}$, the increasing is about 19\%. Also we got the transport demand increasing in 9\% (figure $3-4$ ).

The data show the positive effect of the developing the alternative route for this part of transport network. To receive the data about the transport flows redistribution, the cross elasticity coefficient was obtained. The results are (table 1,2). 


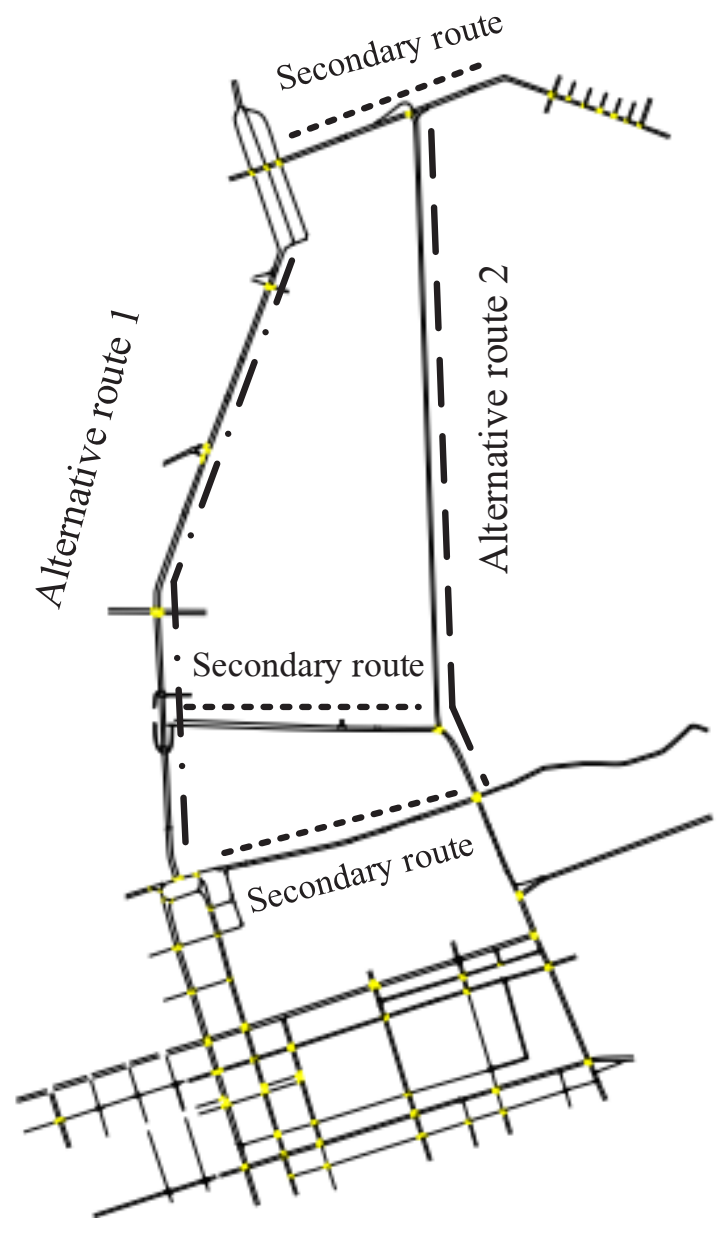

Fig. 2. The boarders of the modelling

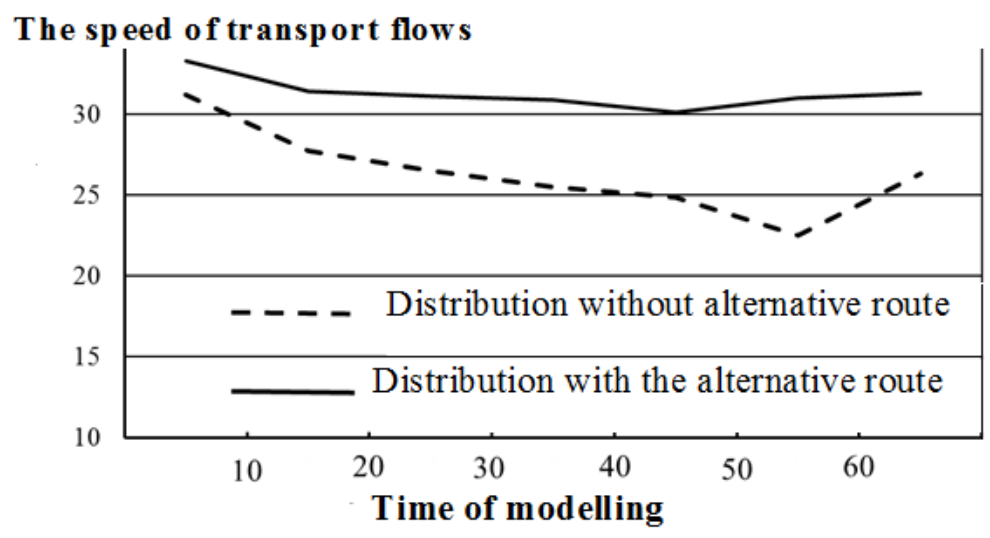

Fig. 3. The speed results of the modelling 


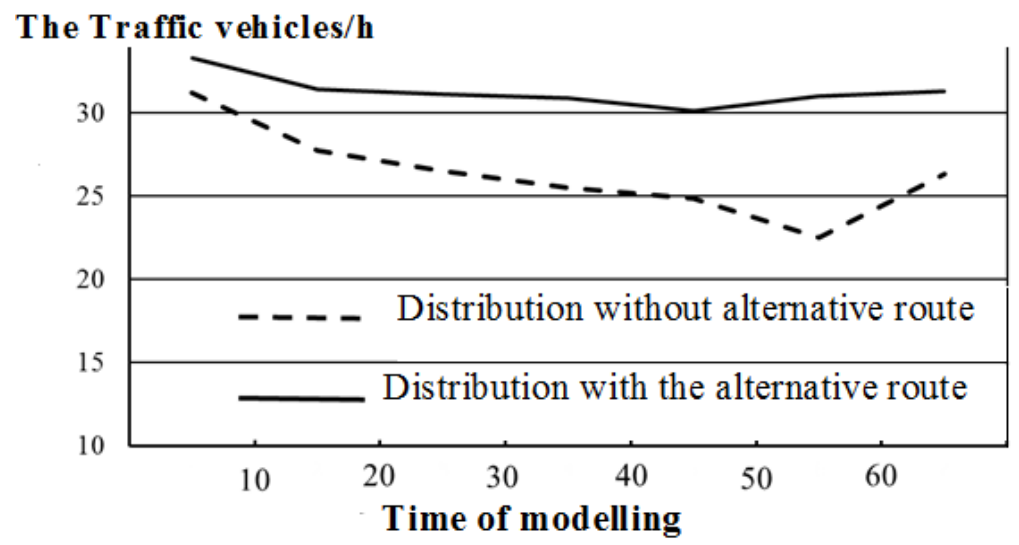

Fig. 4. The traffic results of the modelling

Table 1. The traffic flows redistribution

\begin{tabular}{|l|c|c|c|}
\hline \multirow{2}{*}{ Route code } & \multicolumn{2}{|c|}{ Traffic (vehicles per hour) } \\
\cline { 2 - 4 } & 449 & $\begin{array}{c}\text { Before developing } \\
\text { alternative route }\end{array}$ & $\begin{array}{c}\text { After developing } \\
\text { alternative route }\end{array}$ \\
\hline Alternative route 1 & 451 & 2592 & 1440 \\
\cline { 2 - 4 } & 463 & 738 & 209 \\
\cline { 2 - 4 } & 490 & 3204 & 1962 \\
\cline { 2 - 4 } & 491 & 1968 & 928 \\
\cline { 2 - 4 } & 990 & 3042 & 14027 \\
\cline { 2 - 4 } & 2225 & 2208 & 1389 \\
\cline { 2 - 4 } & 2397 & 2310 & 2219 \\
\hline Alternative route 2 & 2567 & 1488 & 2418 \\
\cline { 2 - 4 } & 2568 & 1716 & 2178 \\
\hline
\end{tabular}

Table 2. Elasticity coefficient

\begin{tabular}{|c|c|}
\hline Route code & Elasticity Coefficient \\
\hline 449 & $-0,429$ \\
\hline 451 & $-0,266$ \\
\hline 463 & $-0,558$ \\
\hline 490 & $-0,361$ \\
\hline 491 & $-0,571$ \\
\hline 990 & $-0,522$ \\
\hline 2225 & $-0,478$ \\
\hline 2397 & $-0,293$ \\
\hline
\end{tabular}

\section{Conclusions}

The elasticity coefficient we obtained is the important measure in the forecasting of the developing alternative routes.

On the base of modeling data, elasticity coefficient we got the results that make us sure in the successful developing of the project. 
Many cities in the world get an experience in the developing alternative routes. Nevertheless, the results of such project are often unpredictable. The statistics shows that just in $24 \%$ of cases failed to shoot targets. Just $32 \%$ are successful. It means that it is necessary to find new approaches to solve this problem. The offered methodic could increase the successful results $[10,11,15,16]$.

\section{References}

1. I. Damnjanovic, Network-Based Decision Support Tool for Toll Roads, Center for Transportation Research University of Texas.109 p.

2. V.V. Zyryanov, A.A. Feofilova, Simulation of evacuation route choice, Journal Transportation Research Procedia, 20, pp. 740-745 (2017)

3. V.V. Zyryanov, Application of microsimulation to forecast the development of transportation infrastructure and traffic management, Journal "Russian roads of the 21st century", Moscow, 3, pp. 37-40

4. O. Krivolapova, Algorithm for Risk Assessment in the Introduction of Intelligent Transport Systems Facilities, Transportation Research Procedia, 20 (2017)

5. E. Ben-Elia, Y. Shiftan, Which road do I take? A learning-based model of route-choice behavior with real-time information, Transportation Research Part A 44, pp. 249-264, (2010)

6. W-C. Chiang, R.A. Russell, Integrating Purchasing and Routing in a Pro pane Gas Supply Chain, European Journal of Operational Research, 154, pp.710-729 (2004)

7. N. Geroliminis, C.F. Daganzo, Existence of urban-scale macro-scopic fundamental diagrams: Some experimental findings, Transportation Research Part B 42, pp 759-770 (2008)

8. A. M. Rao, K. Rao, Measuring urban traffic congestion - a review, International Journal for Traffic and Transport Engineering, 2 (4), pp. 286 - 305 (2012)

9. V. Zyryanov, Simulation of Impact of Components of ITS on Congested Traffic States, 7th European Congress on Intelligent Transport Systems (2008)

10. N. Lerner, J. Singer, E. Robinson, R. Huey, J. Jenness, Driver Use of EnRoute RealTime Travel Time Information. Final Report, 124 p. (2009)

11. G. Jizhen, Z. Changqing, Z. Xueliang VMS Release of Traffic Guide Informationin Beijing Olympics, 8(6), pp. 115-120 (2008)

12. J.W. Godfrey, The mechanism of a road network, Traffic En-gineering and Control, 11,. pp 323-327 (1969)

13. M. Florian, M. Mahut, N. Tremblay, Application of a simulationbased dynamic traffic assignment model, European Journal of Operational Research, 189 (3), pp. 1381-1392, (2008)

14. J.-F. Cordeau, G. Laporte, M.W.P. Savelsbergh, D. Vigo, Vehicle Rout ing .

Transportation, in: C. Barnhart, G. Laporte, (eds.), Handbooks in Operations Re search and Management Science, 14, pp. 367-428 (2007)

15. J. Barcelo, and J. Casas, Stochastic heuristic dynamic assignment based on AIMSUN microscopic traffic simulator, 85th Transportation Research Board 2006 Annual Meeting (2005)

16. Peter H Jesty, Jan Giezen, Jean-François Gaillet, Jean-Luc Durand, Victor Avontuur, Richard Bossom, Gino Franco, European ITS Framework Architecture. Models of Intelligent Transport Systems (2010) 